\title{
Design and Comparison Analysis of Various Flow Configurations in Bipolar Plates via Numerical Simulation
}

\author{
Mohammed Azzam ${ }^{1}$, Zabayyan Qaq ${ }^{1} \&$ Mehmet F. Orhan ${ }^{1}$ \\ ${ }^{1}$ Department of Mechanical Engineering, College of Engineering, American University of Sharjah, PO Box: 26666, \\ Sharjah, United Arab Emirates \\ Correspondence: Mehmet F. Orhan, Department of Mechanical Engineering, College of Engineering, American \\ University of Sharjah, PO Box: 26666, Sharjah, United Arab Emirates.
}

Received: September 5, 2021

Accepted: October 17, 2021

Online Published: October 22, 2021

doi:10.5539/eer.v11n2p41

URL: https://doi.org/10.5539/eer.v11n2p41

\begin{abstract}
Bipolar plates play a major role in the overall performance of fuel cells, hence their proper design and optimization are essential. In this regard, pressure drop across bipolar plates has a major impact on the efficiency. Therefore, it is crucial to minimize the friction between the plate walls and the working fluid, with a proper flow configuration, to eliminate pressure drops. The study, involved the simulation of various modified pin-flow bipolar plate configurations where a comparative analysis was carried out. A parametric study was performed to optimize various designs and operating parameters such as fluid flow, velocity and pressure. Computational fluid dynamics (CFD) was employed for the numerical simulation to ensure the optimum uniformity of fluid distribution. Results showed that the pressure drop is proportional to the velocity magnitude in the laminar region. Moreover, the pressure drop was minimized by eliminating the sharp edges in the flow channels.
\end{abstract}

Keywords: bipolar plate, Computational Fluid Dynamics (CFD), electrochemistry, fuel cell, thermoelectricity

\section{Introduction}

Fuel cells are thermoelectric devices that convert the chemical energy of fuels to electricity without any combustion process. One of the most important advantages of fuel cells that they are environmentally friendly, as they contribute to very low to zero emissions. Environmental concerns are focusing on developing and utilising clean and sustainable energy resources by conversion processes that can replace conventional fossil fuel-based power generation systems. Fuel cells are considered one of the most promising clean and efficient energy conversion technologies (The UAE's Response to Climate Change - The Official Portal of the UAE Government, n.d.)(Ministry of Climate Change and Environment, n.d.) . Apart from their clean nature, fuel cells hold many other advantages such as efficient, immobile, quiet and reliable operation (Wilberforce et al., 2017).

However, fuel cells have some limitations and still need further developments for better commercialization. Some major limitations are high manufacturing cost, fuel storage and distribution. Also, pure fuel (e.g. hydrogen) should be supplied to fuel cells to ensure a longer lifetime. In the presence of impurities, the system performance gradually decreases due to catalyst degradation and electrolyte poisoning. There are six common types of fuel cells which are classified by their electrolytes, namely alkaline fuel cell (AFC), proton exchange membrane fuel cell (PEMFC), direct methanol fuel cell (DMFC), molten carbonate fuel cell (MCFC), phosphoric acid fuel cell (PAFC) and solid oxide fuel cell (SOFC) (Wilberforce et al., 2017)(Larminie \& Dicks, 2003). The basic structure of a fuel cell consists of an electrolyte sandwiched between a negative (anode) and a positive electrode (cathode). Fuel is continuously fed to the cell to produce electricity, water vapor and heat via a reverse electrolysis process (Larminie \& Dicks, 2003).

There is an ongoing effort for further development of fuel cells. For instance, (Wang et al., 2009) developed a three-dimensional CFD model for a proton exchange membrane fuel cell, to investigate the effect of a bipolar plate geometry on efficiency. They adjusted their model to include the effect of a two-phase non-isothermal flow. They also investigated the effect of sub-rib convection of bipolar plates by manipulating the number of inlet and outlet flow channels. They concluded that maximizing the sub-rib convection along a high operating temperature of the fuel cell results in a very poor cell performance due to the dry out phenomena. (Boddu et al., 2009) investigated bipolar plates with various serpentine flow channel configurations using CFD. They highlighted those thinner 
bipolar plates with a smooth and uniform surface assure a better performance and minimizing the number and size of channels allow a lower pressure drop across the bipolar plates.

(Jackson et al., 2014) discussed an optimization mean to reduce the pressure drop across the z-type parallel configuration of bipolar plates using CFD. A discrete model with its corresponding governing equations were employed to derive relationships between the headers and channels. It was concluded that decreasing the Reynolds number of the inlet fluid had significantly reduced the effect on the pressure drop across the bipolar plates.

(Kloess et al., 2009) presented two new unique bipolar plates, namely leaf and lung designs. Which are bio-inspired flow channels combing features from the serpentine design with integration from naturally inspirited designs. The models were tested experimentally and numerically using CFD. It was concluded that both designs assured a uniform flow to the diffusion layer, unlike the serpentine design. Additionally, a lower pressure drop was achieved. Both designs obtained enhancement in the power output by a factor of $30 \%$, unlike the standard serpentine flow design.

(Mohammadi et al., 2013) analysed more extensively the flow behaviour in microchannels of the right triangular manifold. The simulation investigated the low Reynold number behaviour across the channels to ensure the minimal appearance of low dead volumes The conclusion had a visible reflection on the reduced Reynold number; the longer and thinner channels lead to better performance. Yet, increasing the spacing between the channels did not have a noticeable difference in the outcomes.

(Hu et al., 2009) introduced a new design, namely slotted-integrated channel. using CFD. Wilberforce et al. (Wilberforce et al., 2017) evaluated various bipolar plate designs to reduce the pressure drop using CFD. to simulate the modified serpentine, parallel, maze and pin channels. Modifications on each type were done using different optimization methods, mainly combining two bipolar plate geometries to integrate one superior design.

(Chen et al., 2021) proposed a stepped flow field in PEMFC bipolar plates and studied the results using CFD. Results showed that stepped flow field fuel cells have better performance compared to traditional fuel cells; with a net power output improvement of $21.5 \%$. In addition, uniformity of gas distribution and current density were improved.

(Suresh et al., 2011) described a flow field design by improving the local crossflow conditions in a serpentine flow field. The new design was based on splitting the channel into selected regions that were more prone to localized flooding. Results showed that the overall pressure drop was decreased and thus, the parasitic power losses were reduced. Also, many parallel flow field bipolar plate designs were studied and compared to the conventional parallel flow designs (Lim et al., 2017). The main concept used was modifying the flow width, and distributing the channels into multiple stages to facilitate even reactant distribution. Results showed that multiple stages of flow distribution can achieve a well-distributed pressure drop.

As a contribution to the aforementioned ongoing efforts, the objectives of this study are to simulate various bipolar plate configurations via CFD in order to visualize the flow behaviour on the velocity profile and computed pressure drop across the selected bipolar plate designs. Also, manipulating different geometrical aspects of the bipolar plates such as smoothing the sharp edges in the flow path, inlet and outlet. Furthermore, to undertake a parametric study of some design parameters such as the inlet channel curvature and penetration geometry. All these modifications were introduced in this work to optimize the pressure drop reduction. In this regard, the mesh independence validation process is considered to minimize the level of numerical errors, and the best mesh map was selected to obtain the results. In brief, selecting the optimized model will lead to minimize the pressure drop and thus higher power output.

\section{Methodology}

The study made use of the Navier-Stokes (NS) equations of momentum, continuity and energy which were numerically solved via CFD to obtain the results. The 3D model equations of NS are shown in equations (1-5). Conservation of momentum equation,

$$
\begin{aligned}
& u \frac{\partial u}{\partial x}+v \frac{\partial u}{\partial y}+w \frac{\partial u}{\partial z}=-\frac{1}{\rho} \frac{\partial P}{\partial x}+\frac{\mu}{\rho}\left(\frac{d^{2} u}{d x^{2}}+\frac{d^{2} u}{d y^{2}}+\frac{d^{2} u}{d z^{2}}\right)+g_{x} \\
& u \frac{\partial v}{\partial x}+v \frac{\partial v}{\partial y}+w \frac{\partial v}{\partial z}=-\frac{1}{\rho} \frac{\partial P}{\partial y}+\frac{\mu}{\rho}\left(\frac{d^{2} v}{d x^{2}}+\frac{d^{2} v}{d y^{2}}+\frac{d^{2} v}{d z^{2}}\right)+g_{y}
\end{aligned}
$$




$$
u \frac{\partial w}{\partial x}+v \frac{\partial w}{\partial y}+w \frac{\partial w}{\partial z}=-\frac{1}{\rho} \frac{\partial P}{\partial z}+\frac{\mu}{\rho}\left(\frac{d^{2} w}{d x^{2}}+\frac{d^{2} w}{d y^{2}}+\frac{d^{2} w}{d z^{2}}\right)+g_{z}
$$

where, $\rho$ is density, $\mu$ is the dynamic viscosity of the fluid, $u, v, w$ are the velocity components in $\mathrm{x}, \mathrm{y}, \mathrm{z}$ coordinates, respectively. $g$ is the gravitational acceleration component and $P$ is the pressure.

For compressible fluid, $\rho=\rho(x, y, z)$. Thus, continuity equation,

$$
\frac{\partial(\rho u)}{\partial x}+\frac{\partial(\rho v)}{\partial y}+\frac{\partial(\rho w)}{\partial z}=0
$$

Energy equation,

$$
k_{m}\left(\frac{d^{2} T}{d x^{2}}+\frac{d^{2} T}{d y^{2}}+\frac{d^{2} T}{d z^{2}}\right)=0
$$

where, $k_{m}$ is the thermal conductivity. Reynolds number is a ratio of inertial force to viscous force of fluid, expressed in equation (6).

$$
R e=\frac{\rho \vartheta D}{\mu}
$$

where, $D$ is the hydraulic diameter of the inlet and $\vartheta$ is the normal velocity.

Pressure drop $(\Delta p)$ across the bipolar plate is a function of the friction factor and the fluid velocity, which can be calculated from equation (7).

$$
\Delta p=f\left(\frac{L}{D}\right)\left(\frac{\rho \vartheta^{2}}{2}\right)
$$

where, $f$ is the Darcy friction factor and $\mathrm{L}$ is the length of the flow domain.

The mesh generated for each mesh element size is evaluated according to the mesh quality that takes into account the length of each element in the map. Mesh quality was calculated from equation (8).

$$
\text { Quality }=C\left[\frac{\text { volume }}{\sqrt{\left\{\sum(\text { Edge legth })^{2}\right\}^{3}}}\right]
$$

where, $\mathrm{C}$ is a constant that varies according to the type of mesh element geometry.

\section{Modelling}

Four different bipolar plate models of modified pin design (Wilberforce et al., 2017) were evaluated to optimize the pressure drop, velocity magnitude and profile across the plate. The simulations ran at different inlet velocities ranging from 2 to $8 \mathrm{~m} / \mathrm{s}$ at an increment of $2 \mathrm{~m} / \mathrm{s}$. The algorithm used in this simulation is SIMPLE (Semi-Implicit Method for Pressure Linked Equations) (Imbrioscia \& Fasoli, 2014). The solver type is pressure based-double precision. The default relaxation factors of 0.3 for pressure and 0.7 for velocity were used. Also, a total set of 1,000 iterations were ran with a convergence criteria value of $10^{-6}$. All iterations were converged successfully after a certain number of iterations.

\subsection{Mesh Independence Validation}

The meshing process in CFD designs is defined as breaking the geometry into small mesh cells "net" and solving the different governing equations at the nodes of each cell. This is why ensuring the minimization of numerical errors during the computation is essential. This process is called mesh independent validation where each design is meshed with different mesh element sizes using the control engine option in CFD. These computations were repeated till no noticeable difference and variation were obtained after several runs of changing the mesh cell size, as the accuracy of any random mesh design is obtained using the mesh cell size. Different terms are used to describe the effectiveness and precision of a certain mesh design. For example, mesh element quality and the skewness of the grids. It can be concluded eventually that the mesh independence validation is achieved properly. Doing any further attempts with higher mesh cell numbers will never change the final solution of the problem significantly. Mesh validation is done by taking a base mesh element size, and then considering half the current element size. Table (1) shows the mesh element sizes for each run used for the four models to work out the mesh validation: 
Table 1. Different mesh element sizes used for the four models

\begin{tabular}{llll}
\hline & Run 1 & Run 2 & Run 3 \\
\hline First Design & $0.05 \mathrm{~mm}$ & $0.025 \mathrm{~mm}$ & $0.0125 \mathrm{~mm}$ \\
Second Design & $0.1 \mathrm{~mm}$ & $0.05 \mathrm{~mm}$ & $0.025 \mathrm{~mm}$ \\
Third Design & $0.06 \mathrm{~mm}$ & $0.03 \mathrm{~mm}$ & $0.015 \mathrm{~mm}$ \\
Forth Design & $0.06 \mathrm{~mm}$ & $0.03 \mathrm{~mm}$ & $0.015 \mathrm{~mm}$ \\
\hline
\end{tabular}

\subsection{Mesh Selection}

After performing the mesh independent study and selecting the appropriate mesh map with the most suitable mesh element size. Figure (1) shows the results obtained for three runs with different mesh elements.

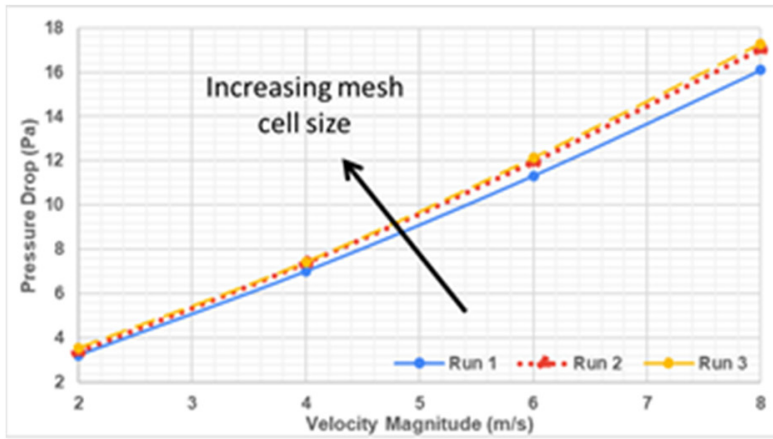

(a)

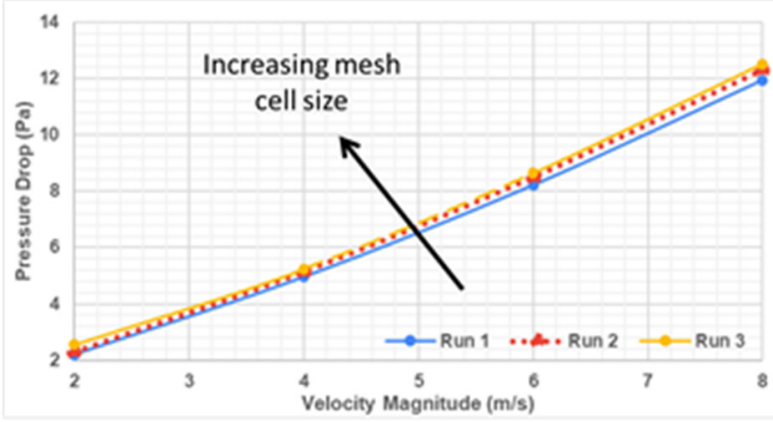

(c)

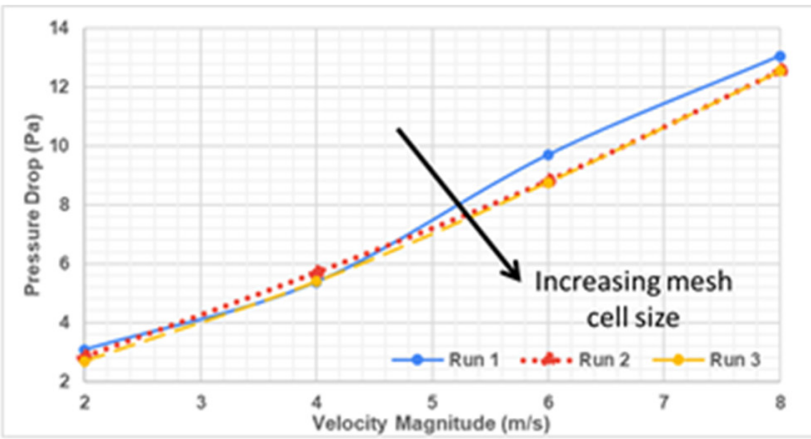

(b)

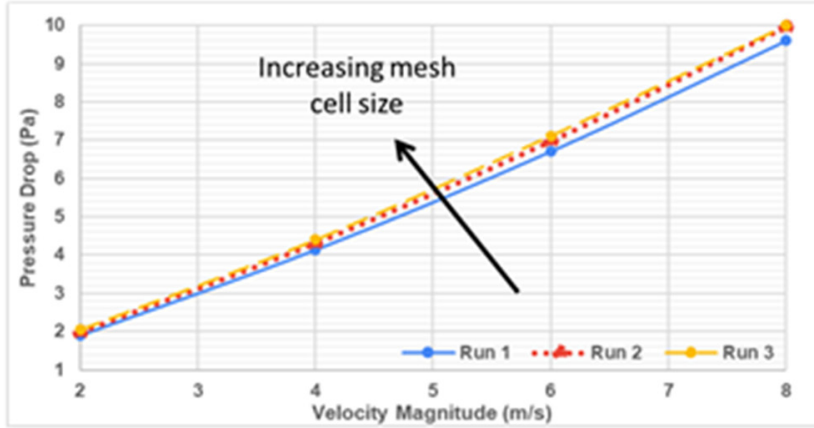

(d)

Figure 1. Pressure drop Vs. velocity magnitude at different mesh cell size. (a) First Design. (b) Second Design.

(c) Third Design. (d) Fourth Design

According to the results, run 3 was selected since no noticeable difference was highlighted. Thus, mesh independence validation for the four different designs was achieved successfully. Table (2) summarizes the mesh statistics. Figure (2) shows the generated mesh for each design, highlighting the critical regions in the design, such as the inlet walls, and between the perforations. All designs had fine mesh where some areas had perfectly mapped mesh.

Table 2. Mesh Statistics

\begin{tabular}{lll}
\hline Design & Number of mesh cells & Average element quality \\
\hline First Design & 479710 & 0.99878 \\
Second Design & 445541 & 0.9206 \\
Third Design & 482731 & 0.97587 \\
Fourth Design & 462084 & 0.957 \\
\hline
\end{tabular}




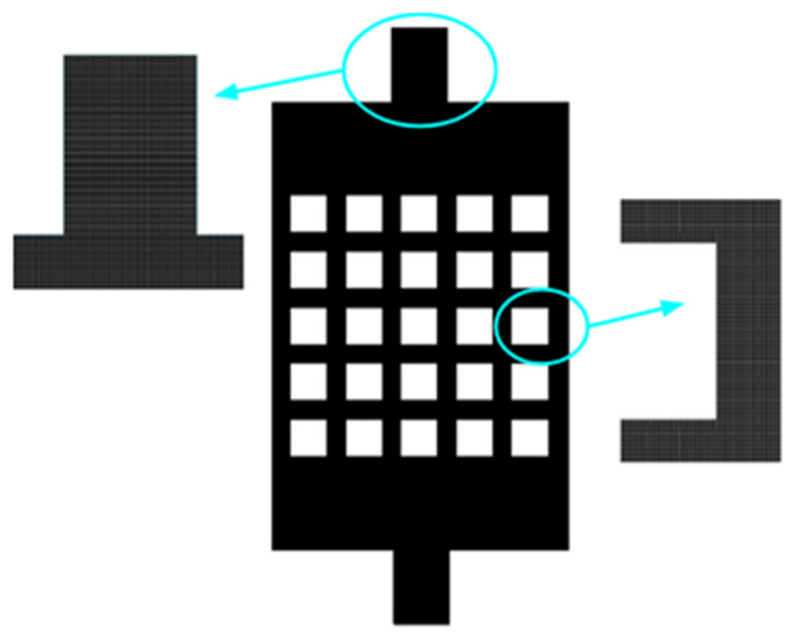

(a)

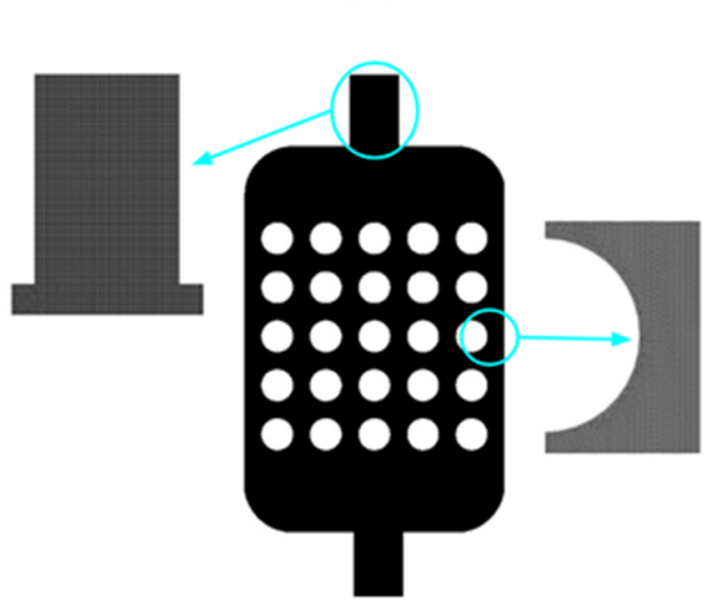

(c)

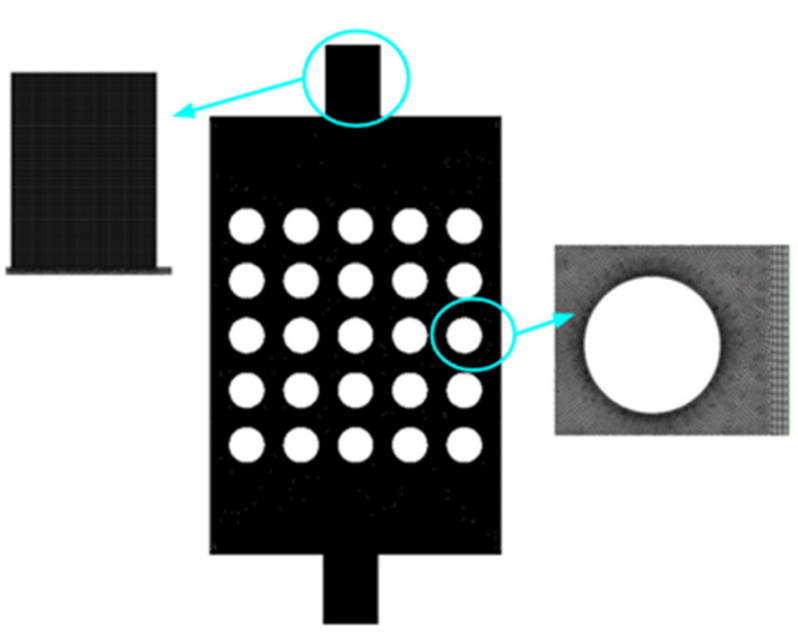

(b)

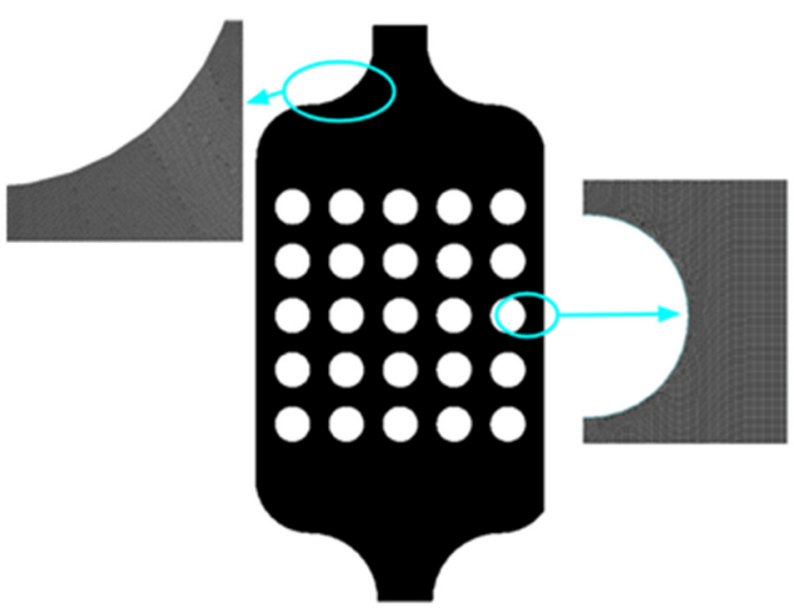

(d)

Figure 2. Overview and zoomed view mesh map for critical regions. (a) First Design. (b) Second Design. (c) Third Design. (d) Fourth Design

\section{Results and Discussion}

Four designs were modelled using ANSYS 2020 R2; velocity and pressure contours were generated for each design at inlet velocities of 2 and $8 \mathrm{~m} / \mathrm{s}$ as shown throughout Figures (3-6).

\section{First design:}

The first design is called the modified pin flow plate design (Wilberforce et al., 2017), shown in Figure (3-a). This design is made to have one inlet and one outlet for the fluid domain where the fluid will have an even distribution throughout the channels. Velocity contours are shown in Figures (3-a, 4-a) when the inlet velocity is 2 and $8 \mathrm{~m} / \mathrm{s}$, respectively. It can be noticed that the velocity at the outlet is higher than the inlet velocity, this is due to gas expansion as the pressure drops. In addition, some regions are noticed to have relatively low-velocity magnitudes; these regions are called the dead zones that can lead to water accumulation and thus, affects the performance of the fuel cell. The pressure contour is shown in Figures (5-a, 6-a) at same inlet velocities ( 2 and $8 \mathrm{~m} / \mathrm{s})$. It can be shown that the pressure is evenly distributed across the horizontal axis, and it reduces when moving vertically towards the outlet. These results match the results obtained in (Wilberforce et al., 2017). This design has square perforations with sharp edges, this is why the pressure drop in this design is relatively high. Pressure drop for the first design was $17.2 \mathrm{~Pa}$ at $8 \mathrm{~m} / \mathrm{s}$. To decrease the pressure, drop across the geometry, a modification was introduced with adjusted geometry of circular perforations, which will be the second design. 


\section{Second Design:}

The second design had the same overall geometry, but the perforations were adjusted to be circles with the same hydraulic diameter of the squared design. The pressure drop for the second design was $12.5 \mathrm{~Pa}$ at $8 \mathrm{~m} / \mathrm{s}$. The pressure drop decreases due to the fact that the sharp edges were eliminated and thus, the fluid flows smoothly around the perforation. In Figures (3-b, 4-b), it can be observed that the velocity contours have the same trend as the previous design, where the outlet velocity is higher than the inlet velocity. It was also observed that the dead zone regions did not change compared to the previous design. The pressure contours are shown in Figures (5-b, $6-b)$, it can be seen that the pressure is distributed equally throughout the plate. It can be noticed that the dead zone regions are mostly found at the corners of the bipolar plate and between the perforations. To reduce the dead zone regions across the bipolar plate, a new modification should be introduced, and this will be the third design.

\section{Third Design:}

The third design was modified to reduce the area of the dead zone, in addition to reducing the pressure drop; the sharp edges of the bipolar plates were converted into curved edges. The pressure drop was reduced to $11.9 \mathrm{~Pa}$ at 8 $\mathrm{m} / \mathrm{s}$. Velocity contours shown in Figures $(3-\mathrm{c}, 4-\mathrm{c})$ are well distributed and it can be noticed that the area of the dead zone regions was reduced near the edges of the bipolar plate and between the perforations. Pressure contours shown in Figures $(5-c, 6-c)$ have the same trend from previous designs, but as stated before, the pressure drop was reduced. Sharp edges at the inlet and outlet will produce a shear force between the plate's walls and the fluid and thus, a pressure drop. This can be avoided by curving these edges; this is where the fourth design is introduced.

\section{Fourth Design:}

The fourth design is a modification of the third design, where the inlet and outlet sharp edges were converted into circular curvatures. As stated before, the pressure drop in the third design was $11.9 \mathrm{~Pa}$ at $8 \mathrm{~m} / \mathrm{s}$, it was reduced in the fourth design to $9.6 \mathrm{~Pa}$ at the same inlet velocity. This is due to reducing the shear stress between the walls and the working fluid, allowing the flow to be distributed more smoothly. Figures (3-d, 4-d) show that the velocity contours are well distributed across the bipolar plate, where the outlet velocity has a higher velocity than the velocity at the inlet. It can be seen that the velocity at the outlet is reduced compared to the previous designs; this is because the area of the outlet had been increased and thus, the velocity decreases. The pressure contour shown in Figures (5-d, 6-d) is evenly distributed across the channels of the bipolar plate. By comparing the fourth design to the first design, it is noticeable that the pressure drop was reduced significantly, the dead zone regions were decreased, and the flow distribution was smoother. These parameters are important in affecting the general performance of the fuel cell.

Figure (7) shows the pressure drop at various velocities for all the designs evaluated in this study. From the figure, the difference between the original (first design) and modified designs, and their associated reduction in the pressure drop can clearly be seen. It's also noticed that the difference between the first and second designs is relatively larger than the difference between the second and the third designs. This can be justified by the fact that the aim of the third modification aim was to reduce the dead zone region, not the pressure drop. 


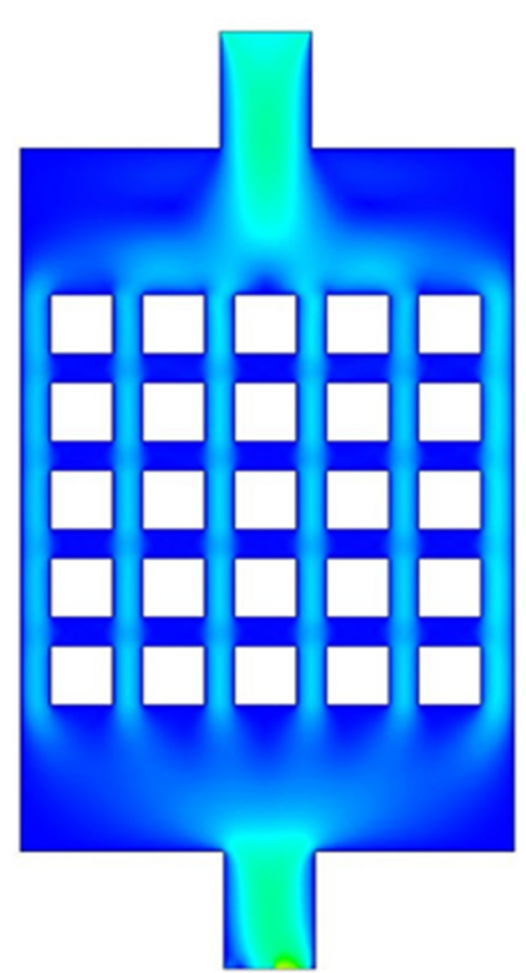

(a)

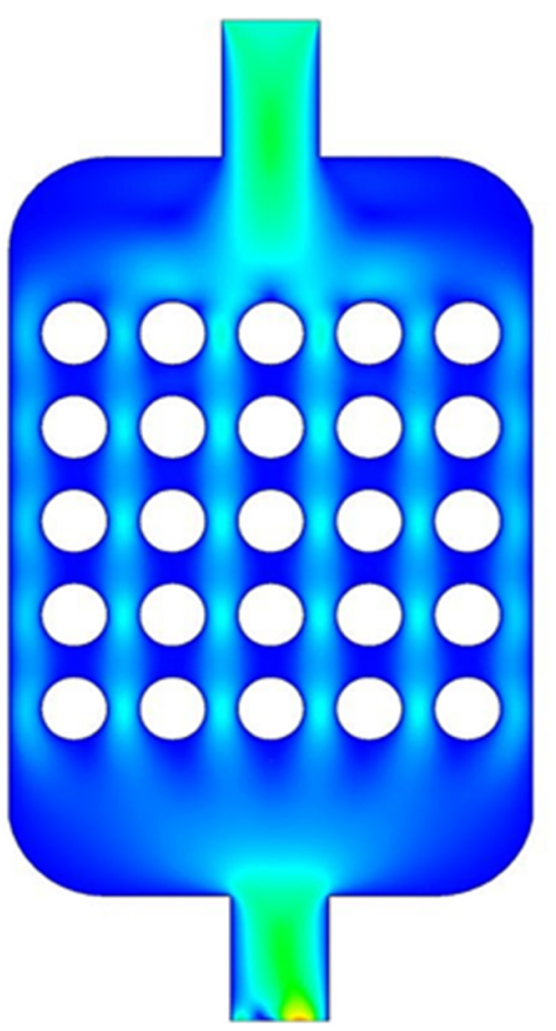

(c)

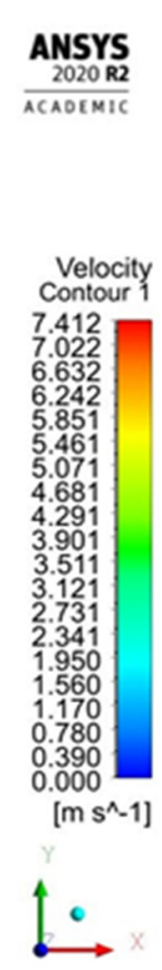

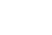

ANSYS

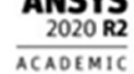

Velocity

6.055

5.418

5.099

4.780

4.462

4.143

3.824

3.506

3.187

2.868

2.549

1.231

1.593

1.275

0.956

0.319

0.000

$\left[\mathrm{m} \mathrm{s}^{\wedge}-1\right]$
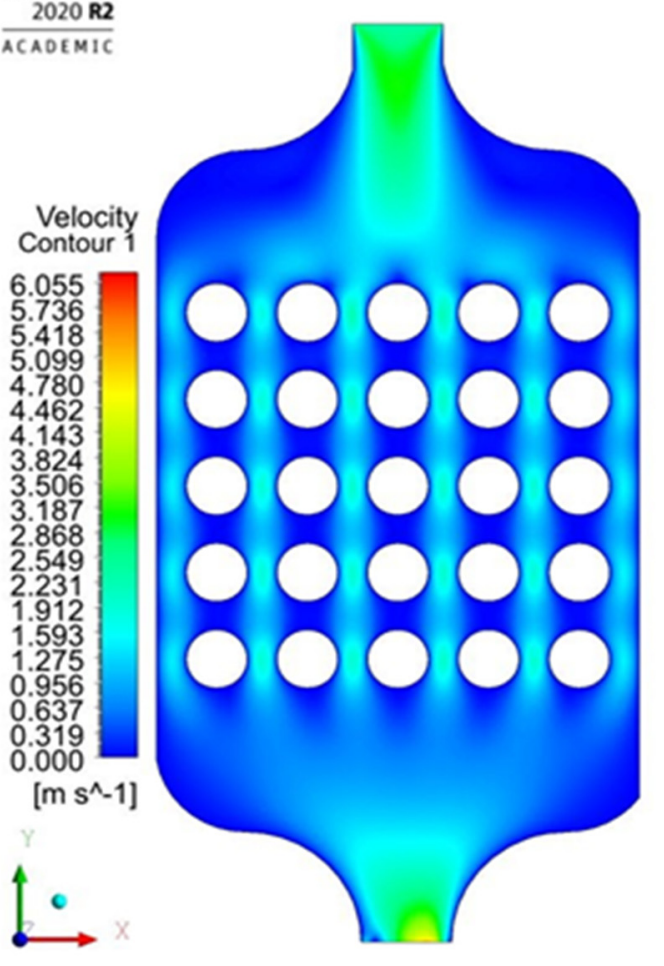

(d)

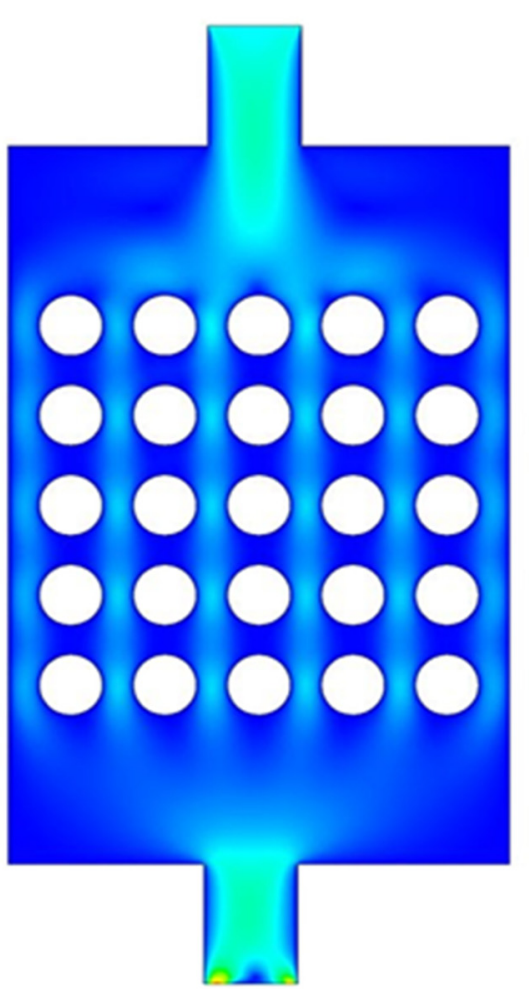

ANSYS

$\frac{2020 \text { R2 }}{A C A D E M 1 C}$

Velocity
Contour 1

7.724

6.911

6.505

6.098

5.28

4.472

4.065

3.659

2.846

2.033

1.626

0.813

0.407

0.000

[m s^-1]

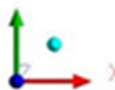

(b)

\section{ANSYS \\ ACADEMIC}

Velocity
Contour 1

4.832

4.564

4.295

4.027

3.490

3.221

2.953

2.685

2.416

1.879

1.611

1.342

1.074

0.805

0.268

0.000

[ $\left.\mathrm{m} \mathrm{s}^{\wedge}-1\right]$

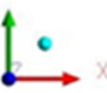

Figure 3. Velocity Contours at an inlet velocity of $2 \mathrm{~m} / \mathrm{s}$. (a) First Design. (b) Second Design. (c) Third Design.

(d) Fourth Design 


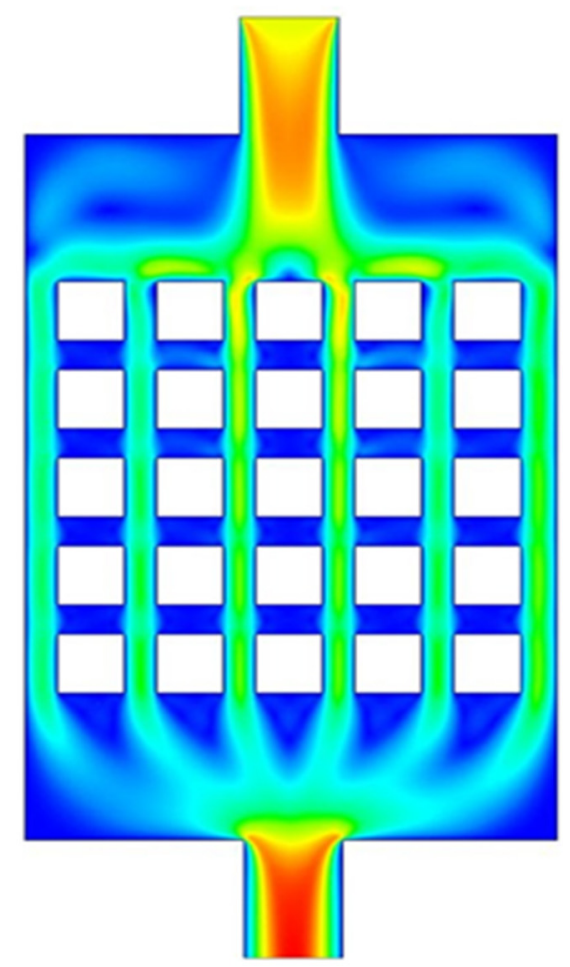

(a)

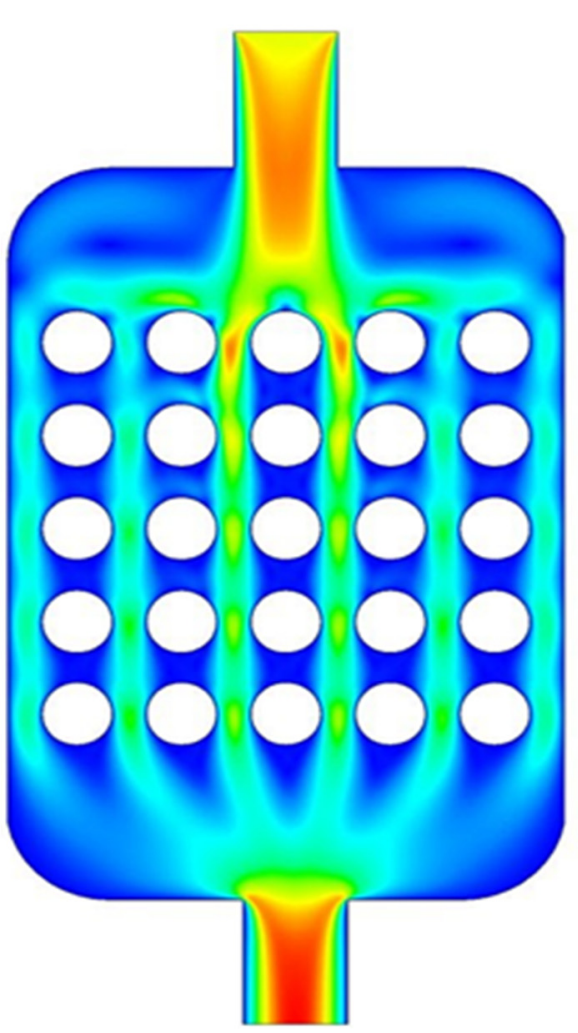

(c)

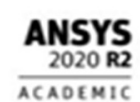

Velocity
Contour 1

11.075
10.492

10.492
9.909

9.326

8.743

7.577

6.995

5.829

5.246

4.663

4.080
3.497

2.914

2.332

1.749

1.166
0.583

0.000

[ $\left.\mathrm{m} \mathrm{s}^{\wedge}-1\right]$

$\stackrel{\leftrightarrow}{\longrightarrow}$

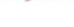

ANSYS

ACADEMI

ACADEMIC

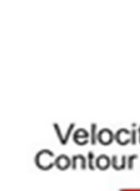

10.855

10.252

9.649

9.046

8.443
7.840

7.840
7.237

6.634

6.031

5.428

4.825

4.222

3.618

3.015

2.412

1.809

1.206
0.603

0.000

[m s^-1]
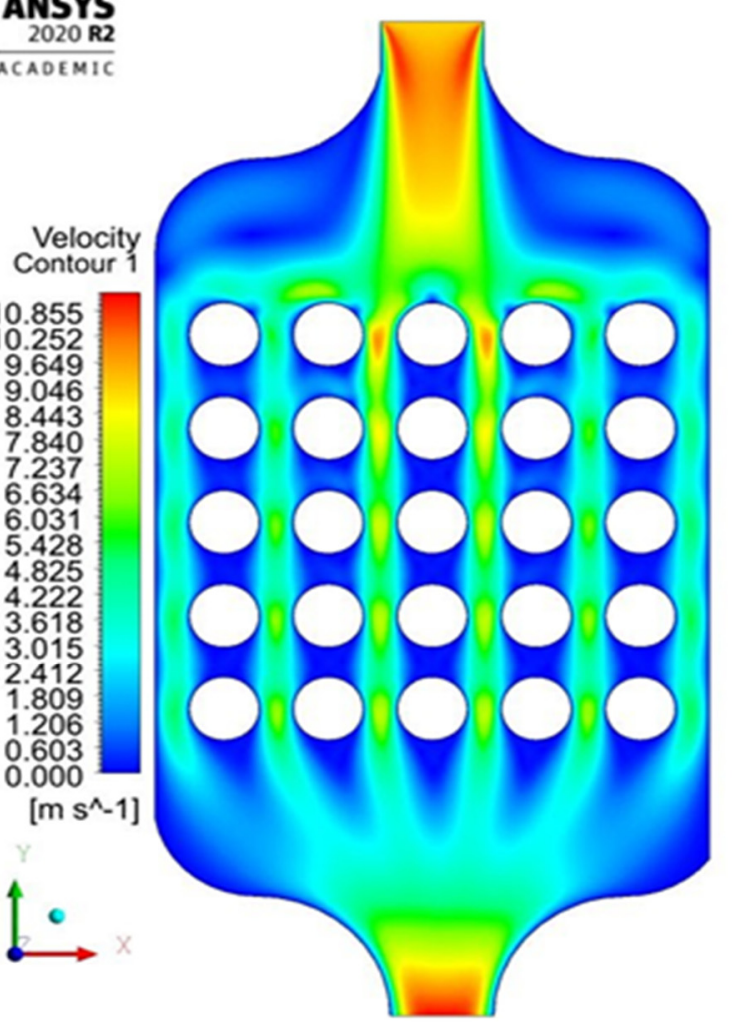

ANSYS

$\frac{2020 \text { R2 }}{\text { ACADEMIC }}$

Velocity
Contour 1

9.540

9.010

7.950

7.420

6.890

6.360

5.830

5.300

4.770

4.240

3.710

3.180

2.650

1.590

1.060

0.530

0.000

[ $\left.\mathrm{m} \mathrm{s}^{\wedge}-1\right]$

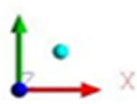

(d)

Figure 4. Velocity Contours at an inlet velocity of $8 \mathrm{~m} / \mathrm{s}$. (a) First Design. (b) Second Design. (c) Third Design.

(d) Fourth Design 


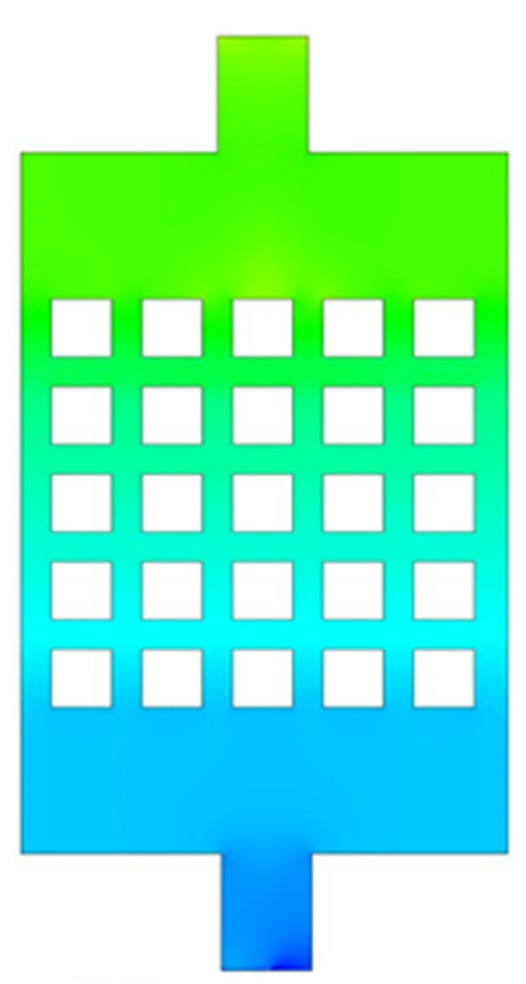

(a)

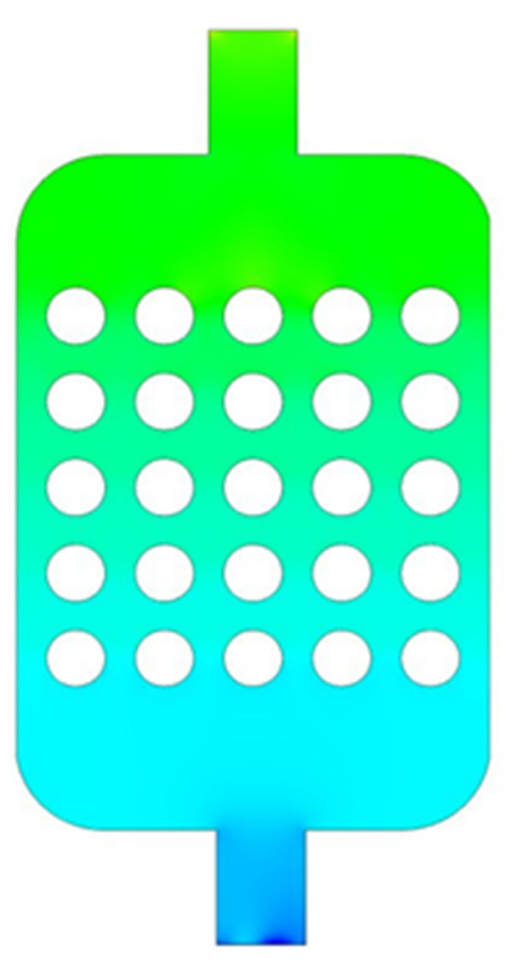

(c)

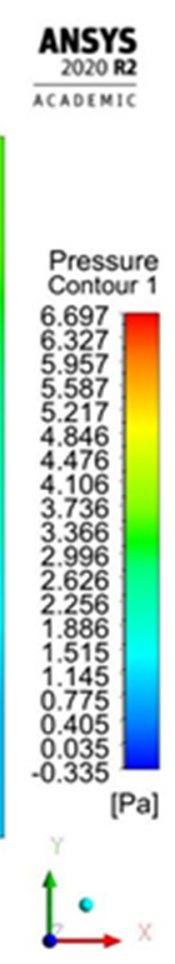

$\frac{\text { ANSYS }}{\frac{2020 R 2}{A C A O E M 1 C}}$

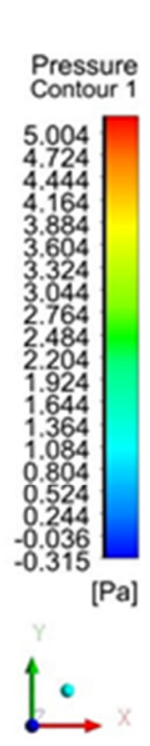

[Pa]

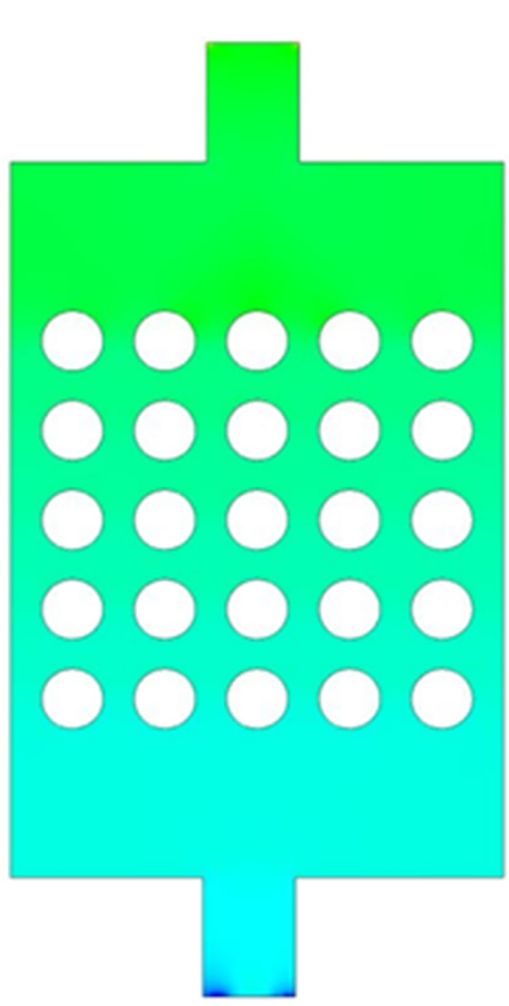

(b)

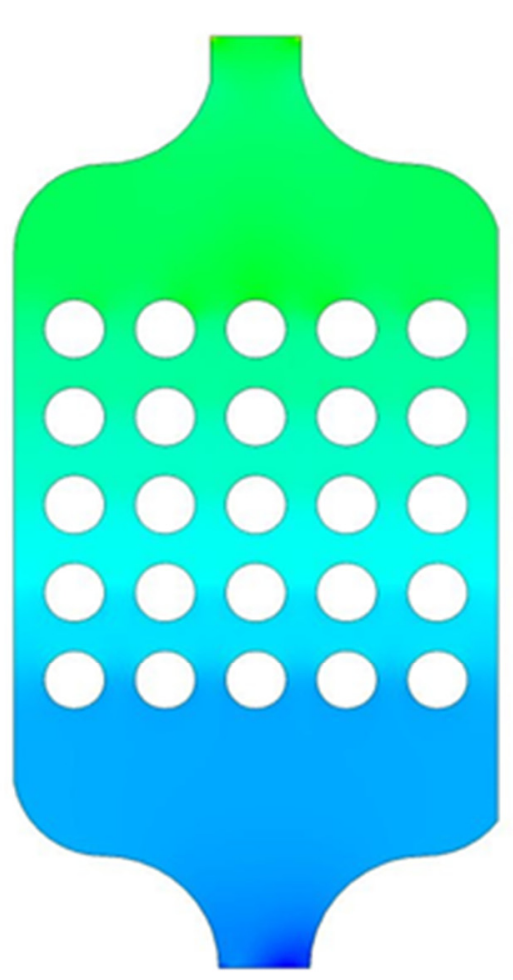

\section{ANSYS \\ 2020 R2 \\ ACAOEMIC}

Pressure Contour 1

4.337 4.096
3.856

3.615

3.375
3.134

2.894

2.413

1.932

1.691

1.210

0.729

0.488

0.248

$-0.233$

[Pa]

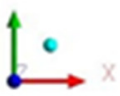

Figure 5. Pressure Contours at an inlet velocity of $2 \mathrm{~m} / \mathrm{s}$. (a) First Design. (b) Second Design. (c) Third Design. (d) Fourth Design 


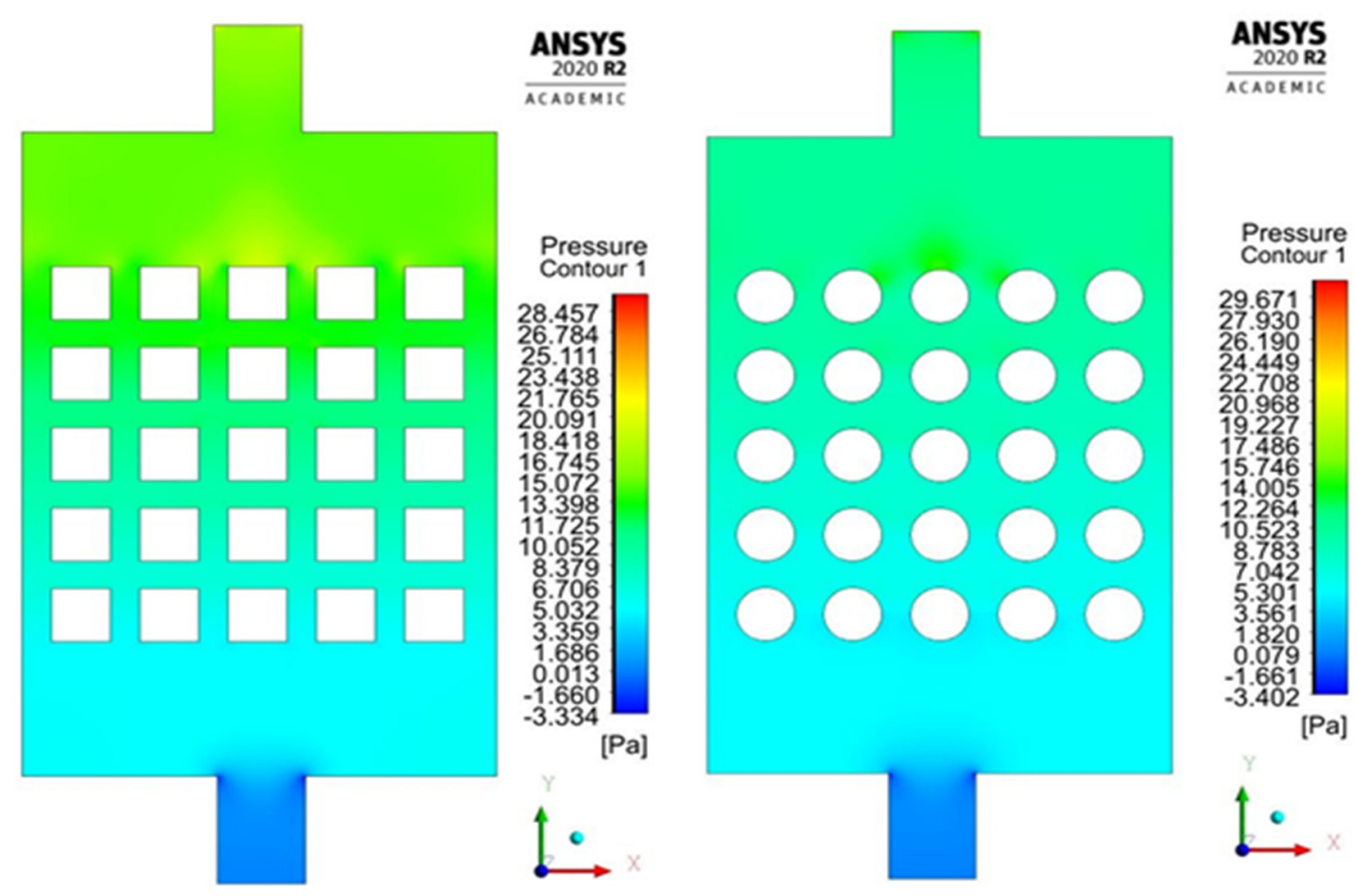

(a)

(b)

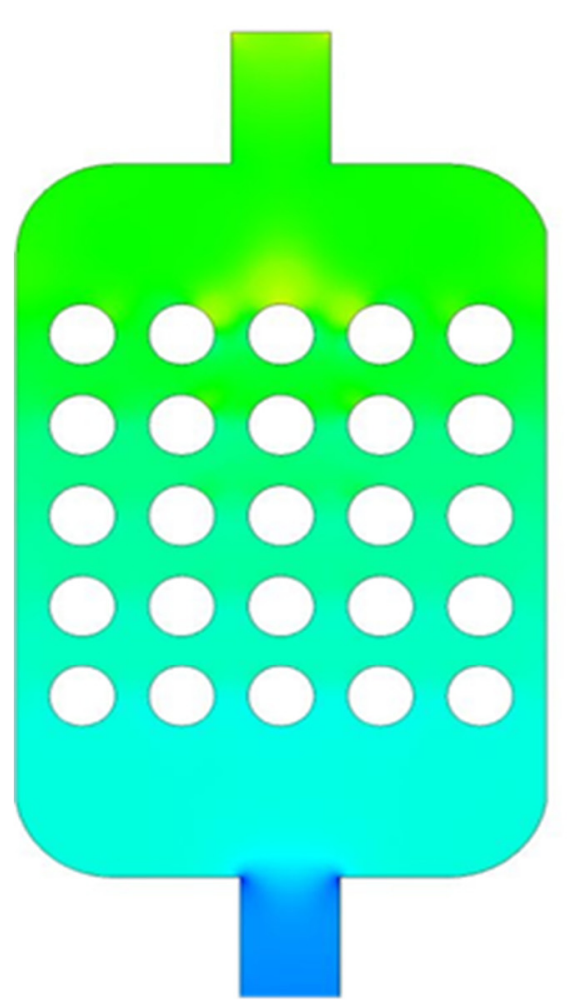

(c)

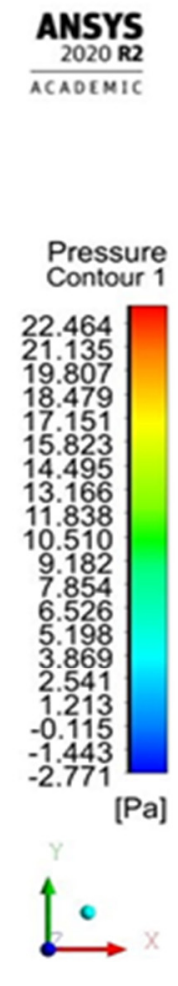

$\underset{2020 \text { R2 }}{\text { ANSYS }}$

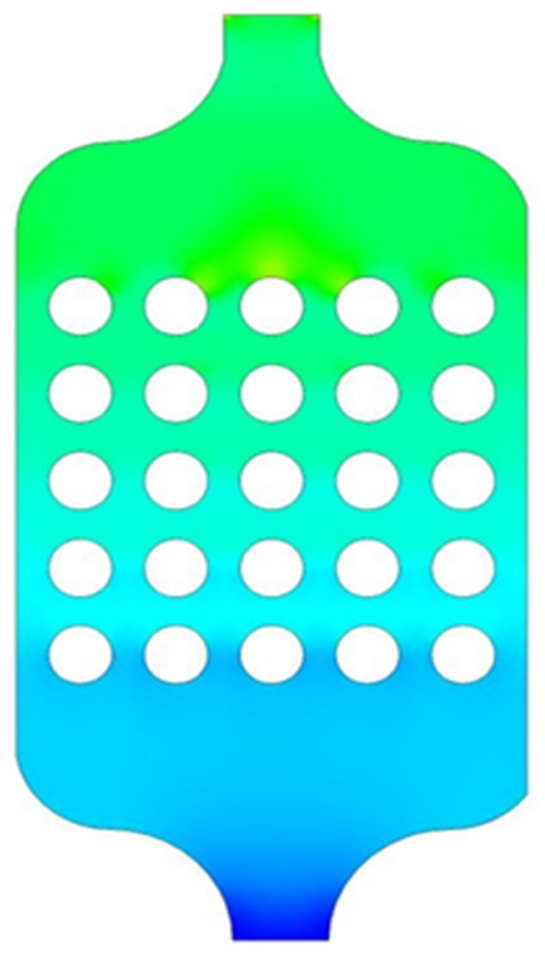

(d)

Figure 6. Pressure Contours at an inlet velocity of $8 \mathrm{~m} / \mathrm{s}$. (a) First Design. (b) Second Design. (c) Third Design. (d) Fourth Design 


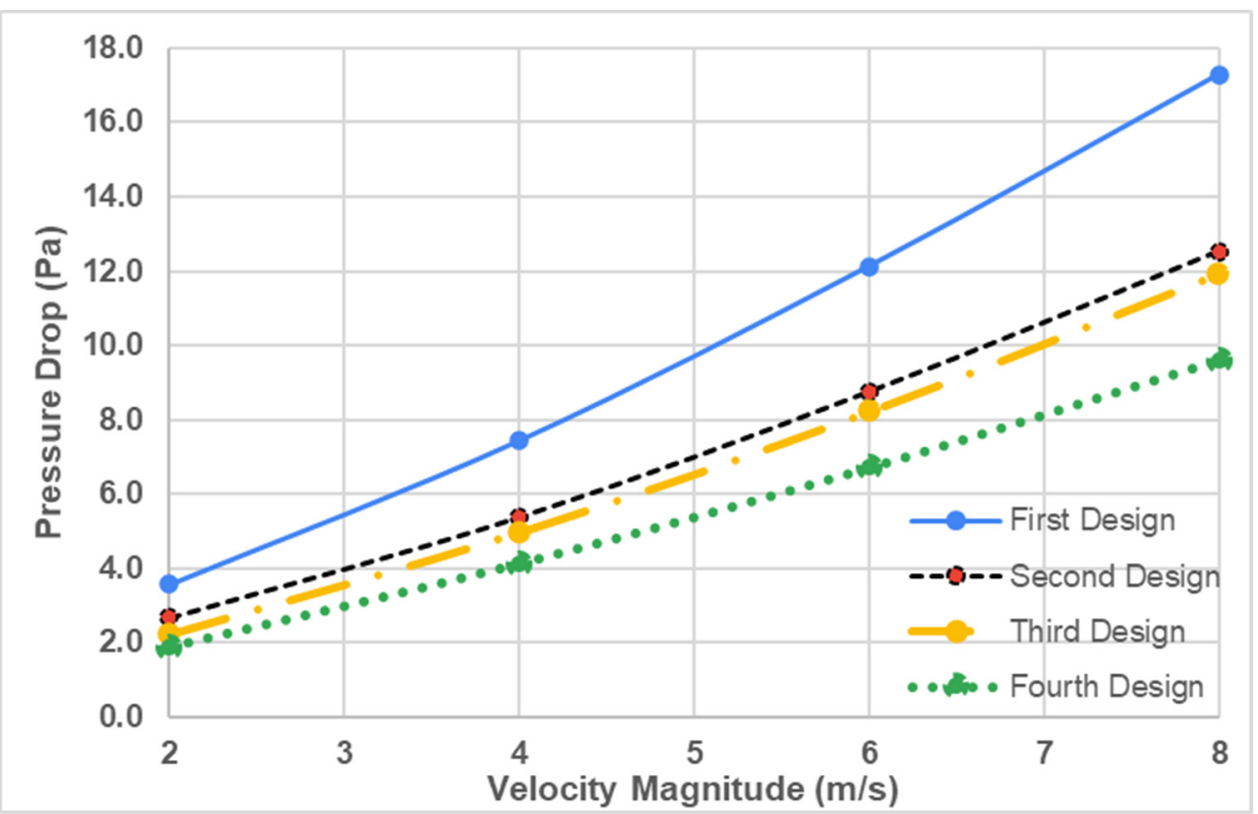

Figure 7. Pressure Drop across the bipolar plate Vs. Inlet Velocity Magnitude for all designs

\section{Conclusion}

In this study, four different bipolar plate models of modified pin design were evaluated to minimize the pressure drop across the plate and ensure a uniform velocity distribution between channels. First, a standard pin flow plate design was evaluated at various inlet velocities to obtain the effect on the pressure drop across the plate. Then, three design modifications were carried out to enhance the performance of the bipolar plate. The main aim was to reduce the pressure drop, the dead zone regions, and obtain uniformity in the flow. It is concluded that eliminating the sharp edges at inlets, outlets and perforations result in smoothening the flow and thus, reducing the pressure drop.

\section{References}

Boddu, R., Marupakula, U. K., Summers, B., \& Majumdar, P. (2009). Development of bipolar plates with different flow channel configurations for fuel cells. Journal of Power Sources, 189(2), 1083-1092. https://doi.org/10.1016/j.jpowsour.2008.12.156

Chen, X., Chen, Y., Liu, Q., Xu, J., Liu, Q., Li, W., Zhang, Y., Wan, Z., \& Wang, X. (2021). Performance study on a stepped flow field design for bipolar plate in PEMFC. Energy Reports, 7, 336-347. https://doi.org/10.1016/j.egyr.2021.01.003

Hu, P., Peng, L., Zhang, W., \& Lai, X. (2009). Optimization design of slotted-interdigitated channel for stamped thin metal bipolar plate in proton exchange membrane fuel cell. Journal of Power Sources, 187(2), 407-414. https://doi.org/10.1016/j.jpowsour.2008.11.047

Imbrioscia, G. M., \& Fasoli, H. J. (2014). Simulation and study of proposed modifications over straight-parallel flow field design. International Journal of Hydrogen Energy, 39(16), 8861-8867. https://doi.org/10.1016/j.ijhydene.2013.11.079

Jackson, J. M., Hupert, M. L., \& Soper, S. A. (2014). Discrete geometry optimization for reducing flow nonuniformity, asymmetry, and parasitic minor loss pressure drops in Z-type configurations of fuel cells. Journal of Power Sources, 269, 274-283. https://doi.org/10.1016/j.jpowsour.2014.06.136

Kloess, J. P., Wang, X., Liu, J., Shi, Z., \& Guessous, L. (2009). Investigation of bio-inspired flow channel designs for bipolar plates in proton exchange membrane fuel cells. Journal of Power Sources, 188(1), 132-140. https://doi.org/10.1016/j.jpowsour.2008.11.123

Larminie, J., \& Dicks, A. (2003). Fuel Cell Systems Explained. In Fuel Cell Systems Explained (2nd editio). John Wiley \& Sons Ltd. https://doi.org/10.1002/9781118878330

Lim, B. H., Majlan, E. H., Daud, W. R. W., Rosli, M. I., \& Husaini, T. (2017). Numerical analysis of modified parallel flow field designs for fuel cells. International Journal of Hydrogen Energy, 42(14), 9210-9218. https://doi.org/10.1016/j.ijhydene.2016.03.189 
Ministry of Climate Change and Environment. (n.d.). UAE National Air Emissions Inventory Project - Final Results. Retrieved February 16, 2020, from https://www.moccae.gov.ae/assets/download/fa2f8dd4/Air Emissions Inventory Report.pdf.aspx?view=true

Mohammadi, M., Jovanovic, G. N., \& Sharp, K. V. (2013). Numerical study of flow uniformity and pressure characteristics within a microchannel array with triangular manifolds. Computers and Chemical Engineering, 52, 134-144. https://doi.org/10.1016/j.compchemeng.2012.12.010

Suresh, P. V., Jayanti, S., Deshpande, A. P., \& Haridoss, P. (2011). An improved serpentine flow field with enhanced cross-flow for fuel cell applications. International Journal of Hydrogen Energy, 36(10), 6067-6072. https://doi.org/10.1016/j.ijhydene.2011.01.147

The UAE's response to climate change - The Official Portal of the UAE Government. (n.d.). Retrieved February 16, 2020, from https://u.ae/en/information-and-services/environment-and-energy/climatechange/theuaesresponsetoclimatechange

Wang, X. D., Duan, Y. Y., Yan, W. M., Lee, D. J., Su, A., \& Chi, P. H. (2009). Channel aspect ratio effect for serpentine proton exchange membrane fuel cell: Role of sub-rib convection. Journal of Power Sources, 193(2), 684-690. https://doi.org/10.1016/j.jpowsour.2009.04.019

Wilberforce, T., El-Hassan, Z., Khatib, F. N., Al Makky, A., Mooney, J., Barouaji, A., Carton, J. G., \& Olabi, A. G. (2017). Development of Bi-polar plate design of PEM fuel cell using CFD techniques. International Journal of Hydrogen Energy, 42(40), 25663-25685. https://doi.org/10.1016/j.ijhydene.2017.08.093 


\section{Appendix}

Nomenclate:

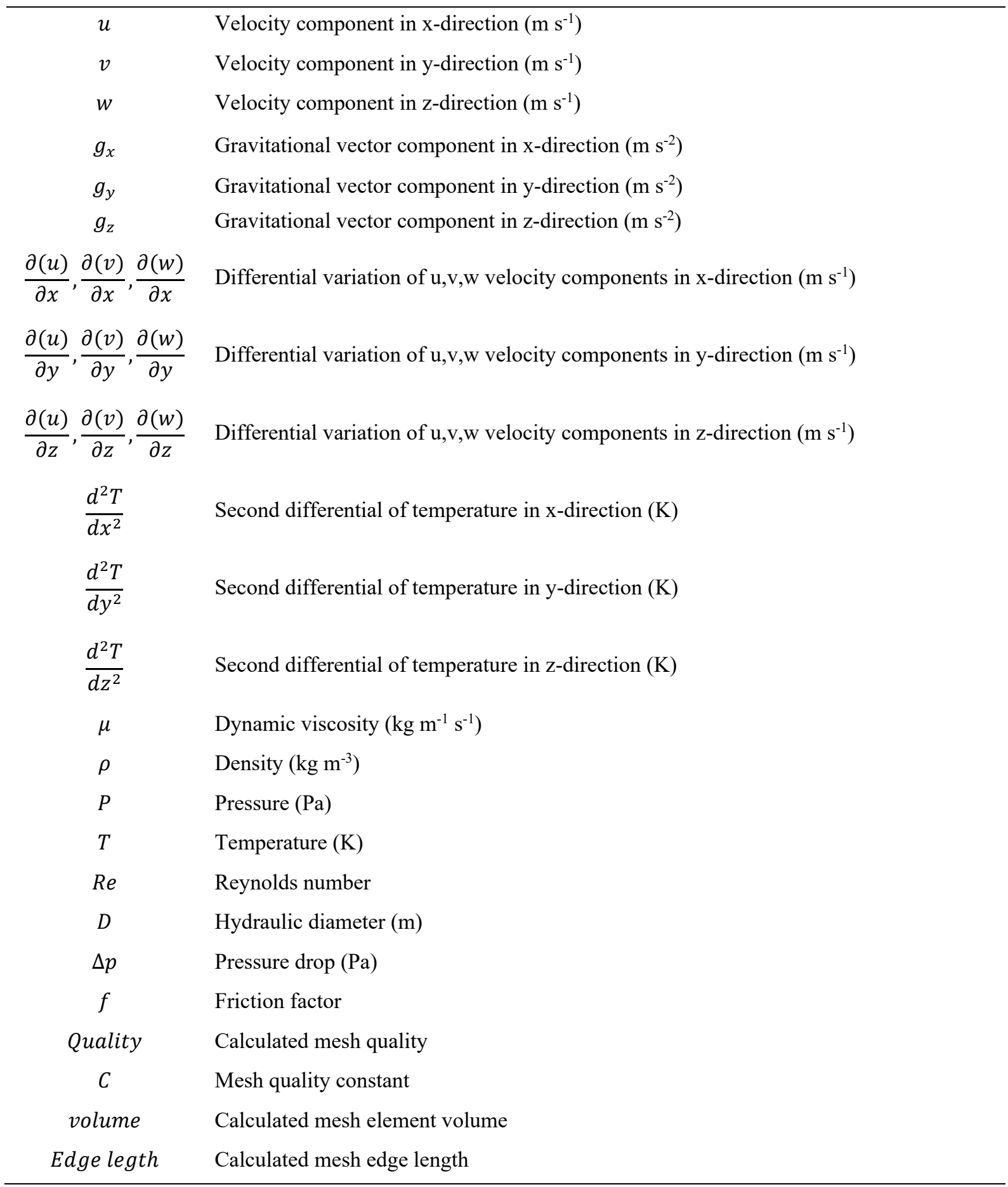

\section{Copyrights}

Copyright for this article is retained by the author(s), with first publication rights granted to the journal.

This is an open-access article distributed under the terms and conditions of the Creative Commons Attribution license (http://creativecommons.org/licenses/by/3.0/). 